\section{MEETING YOUR DESIGN NEEDS}

Henry Schein Minerva are dedicated to delivering expertise in every aspect of surgery layout and installation. The Equipment division uses the latest CAD technology to produce scaled layouts, plans and accurate service drawings,

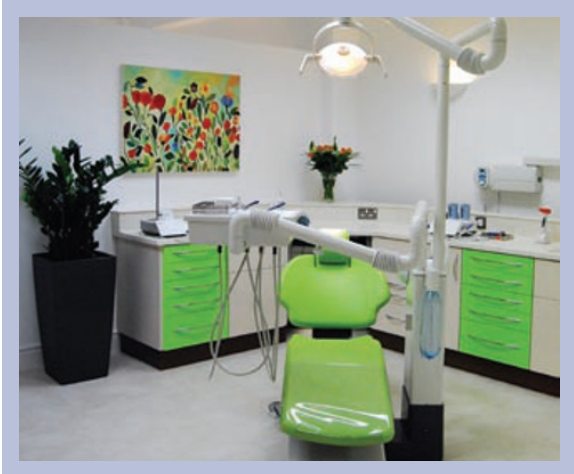

ensuring you achieve the best possible surgery design and maximum patient comfort in the space available.

By offering a wide range of surgery equipment and treatment centres from the world's leading manufacturers, Henry Schein Minerva's team of planners and engineers can create a surgery that meets your exact specifications, whether that be the ultimate in high quality luxury or excellent value for money.

The 'Platinum', 'Gold' and 'Silver' category groups help you compare products based on price, characteristics and features. In addition, Henry Schein Financial Services has several options to help you manage finances and fund practice growth.

Reader response number 54

\section{NOWHERE FOR BACTERIA TO HIDE}

The Cleo II treatment centre's seamless upholstery makes routine cleaning to the highest possible standards an uncomplicated process. Additional features such as touchless on/off sensor controls for the operating light and easy clean membrane switches on the control panel mean that

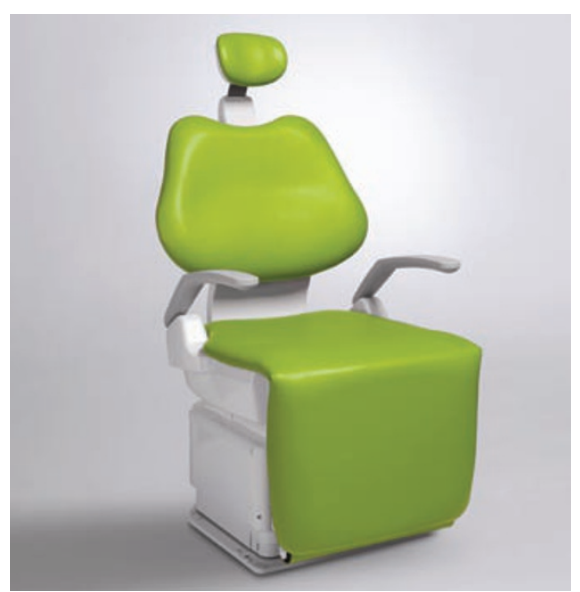

there is nowhere for bacteria to hide.

The Cleo II treatment centre also has soft cushioning providing lumbar and ergonomic support from head to toe. The armchair-like appearance adds reassurance to anxious patients and with removable, foldaway or rotating armrests, patient access for the very young and elderly is made easier.

The centre's small footprint facilitates practitioner movement around the chair even in small surgeries. The ability to position the operator console behind the chair and out of the patient's view makes possible the ideal 'prep and clean' position.

The Cleo II from Takara Belmont is available in air or electric options, the latter of which offers fibre optics, micromotor, endodontic features and digital displays as standard.

Reader response number 55

\section{GENIE IN A SYRINGE}

GC Europe has launched two superior flowable materials: G-ænial Universal Flo and G-ænial Flo, to give patients the best aesthetic, functional and durable restorations.

Unlike other flowable composites the GC materials have a higher filler load and a homogenous dispersion of fillers. The resulting strength and wear resistance are two key features of these flowable materials, opening up the potential for a broader use than standard flowables.

G-ænial Universal Flo is radiopaque and has high viscosity, making it ideal for placement in class IV restorations. It looks like a flowable but behaves like a restorative and can be used for direct restorations, minimum intervention cavities and fissure sealing. The material is highly thixotropic and stays neatly in place, holding its shape. It is virtually selfpolishing with invisible aesthetics.

These restoratives are dispensed through an ergonomically designed syringe that enables smooth delivery of the material, with a tapered tip that means no paste can stick to it. The design also prevents material waste because minimal residual paste remains in the syringe after use.

Reader response number 56

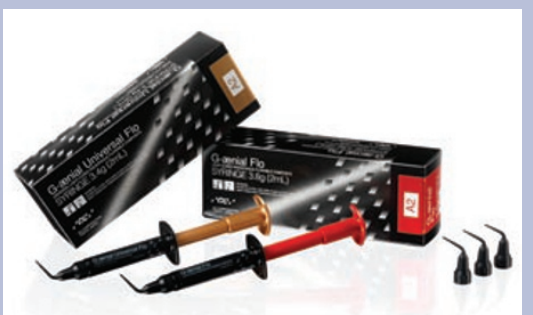

\section{ADVANCED HYGIENE SEMINARS}

Dentisan and Henry Schein Minerva have joined forces to present a series of 'Decontamination: Advanced Hygiene' seminars in 2011, to meet the level of interest in the HTM 01-05 guidelines.

The evening seminars, led by Bob Newsome and Rob Green, are available to both dentists and dental care profes- sionals (DCPs), and provide significant clarity on the issue of decontamination in today's dental practices.

Topics covered will include infection control, transmission methods, detergent and disinfectant action, an explanation of pathogen groups, bacteria, viruses, prions, and a more detailed focus on all areas of the HTM 01-05 guidelines and how to tackle specifics such as hard surface cleaning, biofilm removal and hand care.

Each seminar qualifies delegates for two hours of verifiable CPD, runs from 6-8pm, and includes refreshments.

Seminars will take place in Edinburgh on 19 January; Glasgow on 20 January; Manchester on 2 February; Norwich on 9 March; Salisbury on 17 March; and Leeds on 23 March. Reader response number 57 